\title{
Factors associated to nipple trauma in lactation period: a systematic review
}

\author{
Janaína Silva Dias 1 \\ Tatiana de Oliveira Vieira 2 \\ Graciete Oliveira Vieira 3
} 1-3 Departamento de Saúde. Universidade Estadual de Feira de Santana. Av. Universitária, s.n. Km 03 BR 116. Campus Universitário. Feira de Santana,
BA, Brasil. CEP: 44.031-460. E-mail: janasilvadias@yahoo.com.br

\begin{abstract}
Objectives: To identify the characteristics associated to nipple trauma in nursing mothers and propose a theoretical model explaining in hierarchical levels its determining factors.

Methods: a systematic review of the literature based on the search of epidemiological studies of factors associated to nipple trauma in the databases of Medical Literature Analysis and Retrieval System Online/Pubmed, Literatura Latino-Americana and Caribe em Ciências da Saude (Latin American Literature and Caribbean Health Sciences) and ScienceDirect. The conduct on searching articles occurred until June 2016.

Results: 17 articles were selected which investigated 27 variables and found a significant association between 16 of these variables and nipple trauma. The factors associated to nipple trauma reported in two or more studies were: mother of race/color white or yellow, primiparity, inadequate position between mother and child during breastfeeding and handling the infant incorrectly to the mother's breast. Guidance received on handling and positioning the infant during prenatal care was a protective factor against nipple trauma.

Conclusions: in the theoretical model explaining the factors associated to nipple trauma in hierarchical levels, the variables classified at the proximal level were the most investigated and were identified as risk factors in selected studies, indicating that in the postpartum care period is an important protective factor against nipple trauma.
\end{abstract}

Key words Trauma, Injury, Nipple, Breastfeeding 


\section{Introduction}

It is documented that maternal breastfeeding (MB) confers large benefits to the mother and child's health. ${ }^{1-4}$ However, some problems are faced by nursing mothers during breastfeeding, the example is nipple trauma and may contribute to lower prevalence of maternal breastfeeding. Intervention measurements against its determining factors are necessary for the prevention of diseases. $5-9$

Nipple traumas are characterized by erythema, edema, cracks, fissures, blisters, abrasions and ecchymoses.10-12 In relation to the types of nipple injuries, there is no consensus as regarding to the degree of impairment of the tissue layer on the nipple-areola region. 13,14

The lack of clinical definition for nipple trauma results in disagreements, up to a point that its diagnosis and treatment may be compromised.14 It is suggested that in the context of assisting nursing mothers, nipple trauma may be defined as an alteration in the normal anatomy of the nipple skin with the presence of a primary lesion caused by the modification of the color or thickness and not only as a solution of continuity on the skin. 14

The location of the lesion is observed in the upper part of the body and around the base of the nipple, more often found at the tip of the nipple 10,12,15 involving dermis and epidermis with the presentation in the form of linear ulceration or curved.13 The woman presents symptoms of severe pain on the nipples during breastfeeding. 15

Often nipple traumas are a gateway for pathogenic microorganisms, as mastitis,11,16-18 a Staphylococcus 19 infection and as major complications nipple candidiasis. $20,21 \mathrm{~A}$ study was carried out during the national vaccination campaign formed by mothers of children under the age of one, and found that lactational mastitis was more prevalent among women who had nipple fissure. 22

Among the various approaches for the prevention of nipple trauma, there is an attention in the relation to the positioning and the adequate handling of the infant to the mother's breast, $22-24$ as the injury has been related to the strong pressure exerted on the nipple or the friction of the child's mouth during the suction, this may come as a result of inadequate handling. 15

The survey on factors associated to nipple injury is the utmost importance basis on clinical practice for health professionals, as well as for directing intervention measurements and consequently increasing the duration of maternal breastfeeding. This current study aimed to identify the factors asso- ciated to nipple trauma, through a systematic review of literatures, additionally to propose a theoretical model explaining its determinants in hierarchical levels.

\section{Methods}

This is a systematic review of literatures on the factors associated to nipple trauma in the lactational period, in which a pre-established protocol was used for the search, the selection and data collection, based on Preferred Reporting Items for Systematic Reviews (PRISMA) guidelines for meta-analysis studies and systematic review. 25

The review was based on searches of indexed publications in the following databases: Medical Literature Analysis and Retrieval System Online (MEDLINE)/PubMed, through the National Center for Biotechnology Information (NCBI) 26 platform at http://www.ncbi.nlm.nih.gov/pubmed, Literatura Latino-Americana e do Caribe em Ciências da Saúde (Latin American Literature and Caribbean Health Sciences) (LILACS), by the Biblioteca Virtual em Saúde (Virtual Health Library) (BVS)27 at http://regional.bvsalud.org and ScienceDirect 28 database at http://www.sciencedirect.com/science/ search. As a complementary form of bibliographic search, the strategy of comparing the references cited in each reviewed article with the bibliography has been adopted to obtain the aforementioned above.

In order to ensure the searches, Descritor em Ciências da Saúde (Descriptor in Health Sciences) (DeCS) was consulted. The terms used in the search were: "(((trauma [Title/Abstract]) or sore [Title/Abstract]) or breastfeeding [Title/Abstract]) and nipple [Title/Abstract])))". There was no delimitation in the publication period or language restriction. On ScienceDirect database, a filter was used "trauma or sore or breastfeeding and nipple [All Sources (Medicine and Dentistry, Nursing and Health Professions, Psychology, Social Sciences)]" to view the studies of interest. The conduct of searching articles occurred until June 2016.

The inclusion research criteria were considered as: epidemiological studies with quantitative analysis of factors associated to nipple trauma in breastfeeding women. Studies based on literature reviews (systematically or not), research involving specific populations, absence of abstract and study pilot were excluded. Two independent reviewers conducted the searches and assessed the titles and abstracts of the obtained references. All potentially eligible publications for reading in full were 
selected. The inclusion of the articles and data extraction in the review were also conducted independently, the compared results and the disagreements were solved consensually between both reviewers. In the event of non-agreement between the peers, a third reviewer was consulted.

The appraisal of the quality of the studies were performed based on the type of study, presence of a structured abstract, introduction with background and justification; method on population recruitment; selection of the population/sample; data collection instrument; non-response informed rate; interviewers' training; performance on statistical analysis; study limitation and considered biases; interpreted results according to evidence and general results. The qualification criteria will correspond to a scale 29 adapted for this study with a maximum score of 29 points for each article. "Score zero" was considered when the information was not specified in the text, or did not meet the minimum criteria for the classification of quality.

The data extraction was performed by means of the structured form. Once completed the form, the data entry was performed, including: the reference of the article (with the last name of the first author, journal and the year of publication); the study site and the year of data collection; type of study and numbered sample assessed; the objective of the study; statistical analysis applied; prevalence/incidence of the outcome in the study population; factors associated to nipple trauma, as well as the factors that did not obtain the statistical significance level determined.

Aiming to build a theoretical model, the association found between the factors investigated and nipple trauma were analyzed individually, highlighting and quantifying the following aspects: in how many studies were these factors used and how many identified the association to the outcome.

The last step of the study was the construction of a hierarchical model with the organization of the factors listed in the systematic review in levels according to the proximity of the outcome. Four levels of determinants were proposed: 1- distal (individual maternal characteristics and family, related to the characteristics prior to the pregnancy); 2- distal intermediaries (characteristics of prenatal care); 3 proximal intermediaries (characteristics related to childbirth care); 4- proximal characteristics (maternal characteristics of neonates and health care services, related to postpartum and the process of maternal breastfeeding). 30,31

\section{Results}

In the electronic search 531 articles were found and removed six repeated articles. Evaluated 525 titles and summaries, which 493 references were excluded for not meeting the pre-established criteria and 32 articles were selected for full text reading. Two articles were considered as loss due to the unavailability of the acquisition of the work and five articles were added from the lists of references from the selected articles, resulting in a total of 35 papers that were read thoroughly (Figure 1).

After reading 18 references, three articles used a specific population of premature neonates and seropositive women for the Human Immunodeficiency Virus (HIV), two study pilots, a case study and 12 references for not assessing nipple trauma as an outcome were excluded. At the end of this process, 17 studies met the inclusion criteria (Figure 1).

As for the quality of the studies, no evaluated article obtained the maximum score of 29 points, according to the reference standard applied. The result of the methodology qualification from the selected articles was between 11 to 21 points (Table 1). In relation to the research outline, six studies were cross-sectional, three cohort studies, two casecontrols and six intervention studies. 10 studies were conducted in South America (Brazil, Chile and Uruguay), two in Europe (Italy and Denmark), one in Africa (Libya) and four in Australia. The smaller sample was comprised of 60 women and the largest constituted of 1,020 participants (Table 2).

The prevalence of nipple trauma found in the studies was between $26.7 \%$ to $52.75 \%$ and the incidence of $16 \%$ to $100 \%$. Among the methods of analysis used, four studies used the logistic regression as a multivariate method. In Table 2 shows the variables associated to nipple trauma and the variables with no statistical significance. In Table 3 outlines the number of times each variable was investigated and associated to the outcome of the study.

The factors associated to nipple trauma were organized in the respective hierarchical model levels, constructed from the variables studied (Figure 2). At the distal level, which included the individual maternal characteristics and family, it is understood: mother's race/color white or yellow, 32,33 primiparity, $32,34,35$ presence of nipple fissure in previous pregnancies 35 and mother does not live with a partner. 34 
Figure 1

Flowchart of the selection process of studies included in the systematic review on factors associated to nipple trauma in lactational period.

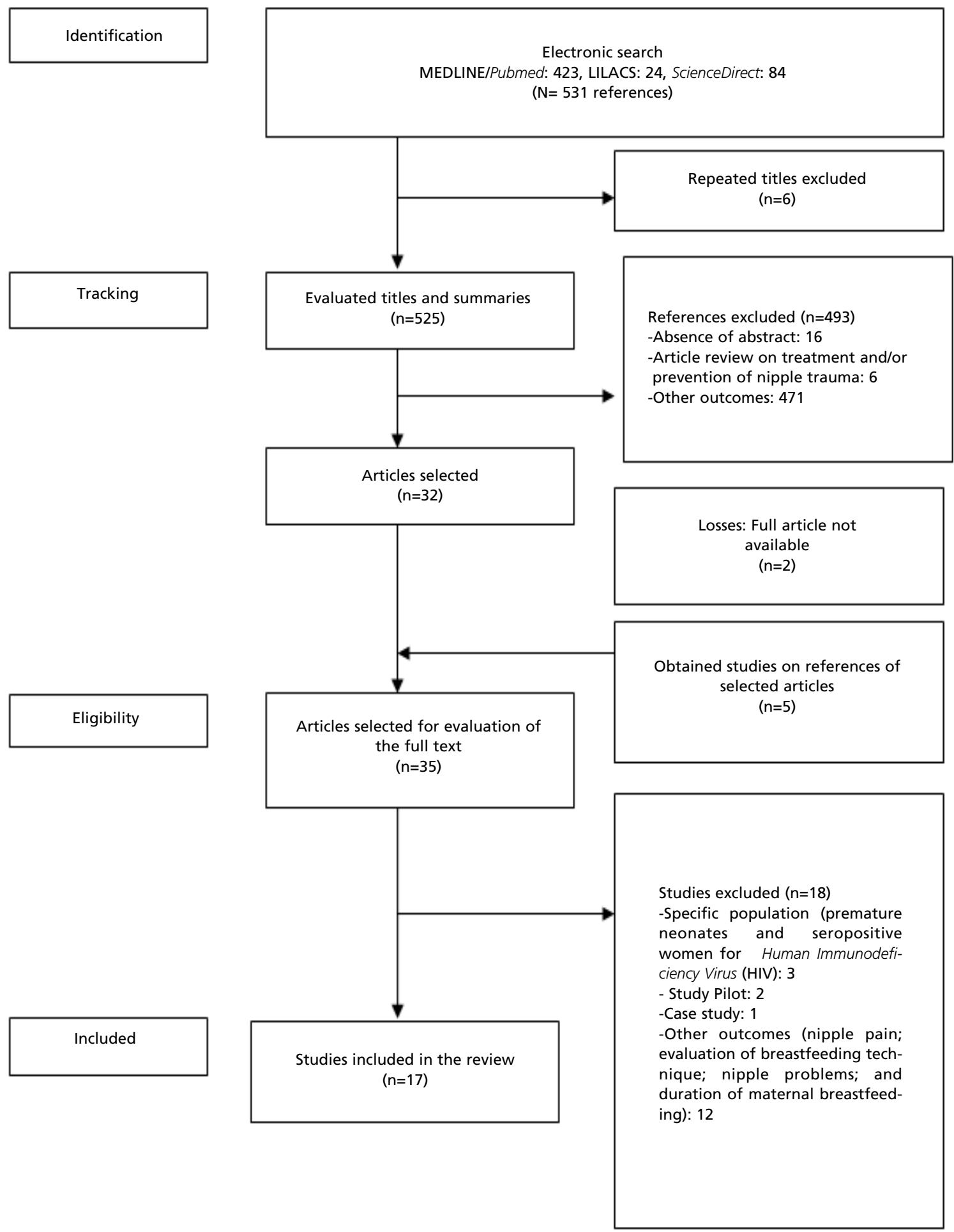

Source: Moher et al.25 


\begin{tabular}{|c|c|c|c|c|c|c|c|c|c|c|c|c|c|c|c|c|c|}
\hline Score the quality criteria & 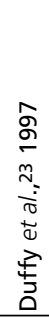 & 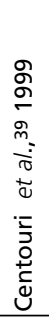 & 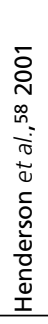 & 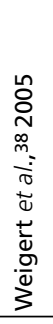 & 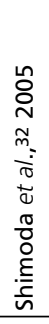 & 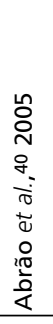 & 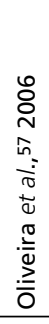 & 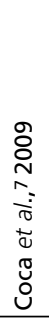 & 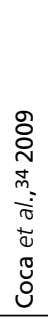 & 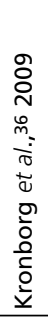 & 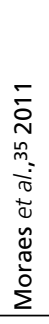 & 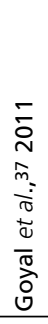 & 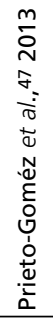 & 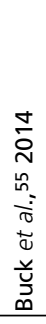 & 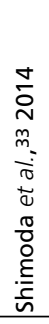 & 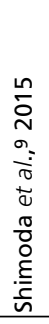 & 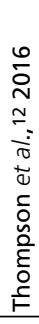 \\
\hline $\begin{array}{l}\text { Types of study: Intervention= } \\
5 ; \text { Cohort }=4 ; \text { Case-control= } 3 \\
\text { Cross sectional= } 2 ; \text { Case study= } \\
1\end{array}$ & 5 & 5 & 5 & 4 & 2 & 2 & 5 & 3 & 3 & 5 & 2 & 2 & 2 & 4 & 2 & 5 & 4 \\
\hline Structured abstract= 1 & 1 & * & 1 & 1 & * & * & * & 1 & * & 1 & 1 & 1 & 1 & 1 & * & 1 & 1 \\
\hline $\begin{array}{l}\text { Introduction with background } \\
\text { and justification }=1\end{array}$ & 1 & 1 & 1 & 1 & 1 & 1 & 1 & 1 & 1 & 1 & 1 & 1 & 1 & 1 & 1 & 1 & 1 \\
\hline $\begin{array}{l}\text { Population recruitment: } \\
\text { National= } 3 \text {; Local residents= } \\
2 ; \text { users of units }=1\end{array}$ & 1 & 1 & 1 & 1 & 1 & 1 & 1 & 1 & 1 & 1 & 1 & 1 & 1 & 1 & 1 & 1 & 1 \\
\hline $\begin{array}{l}\text { Selection of the } \\
\text { population/sample: Census }=6 \text {; } \\
\text { simple random }=5 ; \text { systemati- } \\
\text { cally }=4 ; \text { stratified }=3 ; \text { by con- } \\
\text { glomerates }=2 ; \text { convenience }=1\end{array}$ & 1 & 1 & 1 & 5 & 1 & 1 & 5 & 1 & 1 & 1 & 1 & 1 & 1 & 1 & 1 & 1 & 1 \\
\hline $\begin{array}{l}\text { The data collection instru- } \\
\text { ment: validated and standar- } \\
\text { dized= } 3 ; \text { validated= } 2 \text {; stan- } \\
\text { dardized= } 1\end{array}$ & 3 & 1 & 3 & 3 & 1 & 3 & 3 & 1 & 1 & 3 & 3 & 3 & 3 & 1 & 1 & 1 & 1 \\
\hline $\begin{array}{l}\text { Non-response informed rate }= \\
1\end{array}$ & 1 & 1 & 1 & 1 & 1 & * & 1 & * & * & 1 & * & 1 & * & 1 & 1 & 1 & * \\
\hline Interviewers' training= 1 & 1 & * & * & 1 & 1 & 1 & 1 & 1 & 1 & 1 & 1 & 1 & 1 & 1 & 1 & 1 & 1 \\
\hline Performed statistical analysis $=1$ & 1 & 1 & 1 & 1 & 1 & 1 & 1 & 1 & 1 & 1 & 1 & 1 & * & 1 & 1 & * & 1 \\
\hline $\begin{array}{l}\text { Study limitations and conside- } \\
\text { red biases = } 1\end{array}$ & 1 & * & 1 & 1 & * & * & 1 & 1 & * & 1 & * & 1 & * & 1 & * & 1 & 1 \\
\hline $\begin{array}{l}\text { Interpreted results according } \\
\text { to evidence }=1\end{array}$ & 1 & 1 & 1 & 1 & 1 & 1 & 1 & 1 & 1 & 1 & 1 & 1 & 1 & 1 & 1 & * & 1 \\
\hline $\begin{array}{l}\text { Scale of general results: any- } \\
\text { where in the world= } 5 \text {; conti- } \\
\text { nents= } 4 \text {; the same country= } 3 \text {; } \\
\text { the same geographical } \\
\text { region= } 2 \text {; specific popula- } \\
\text { tion=1 }\end{array}$ & 1 & 1 & 1 & 1 & 1 & 1 & 1 & 1 & 1 & 1 & 1 & 1 & 1 & 1 & 1 & 1 & 1 \\
\hline Maximum score $=29$ & 18 & 13 & 17 & 21 & 11 & 12 & 21 & 13 & 11 & 18 & 13 & 15 & 12 & 15 & 11 & 14 & 14 \\
\hline
\end{tabular}

*The score equal to zero when the information was not specified in the text or when did not meet the defined criteria. Source: adapted from Vieira et al.29 


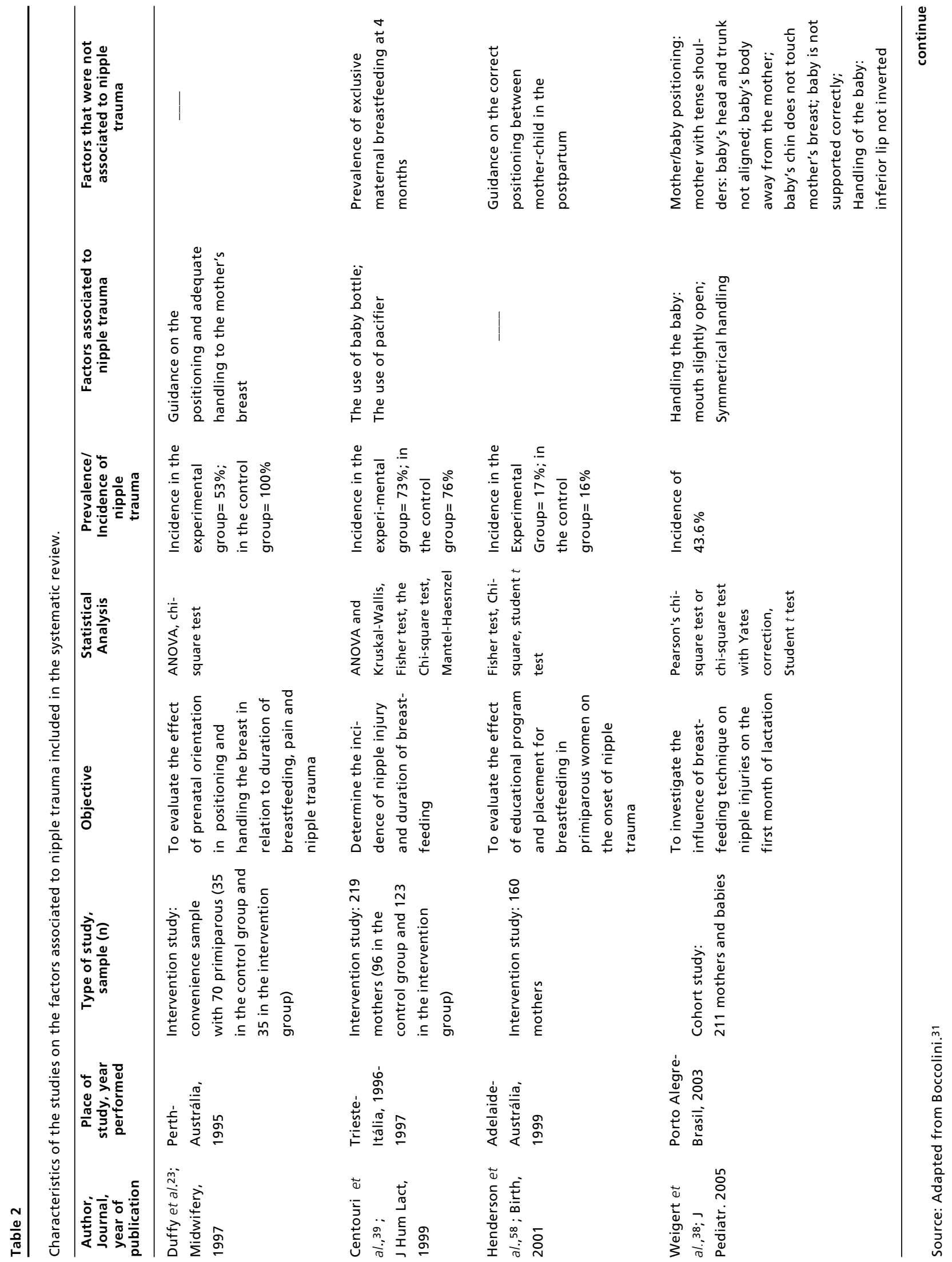




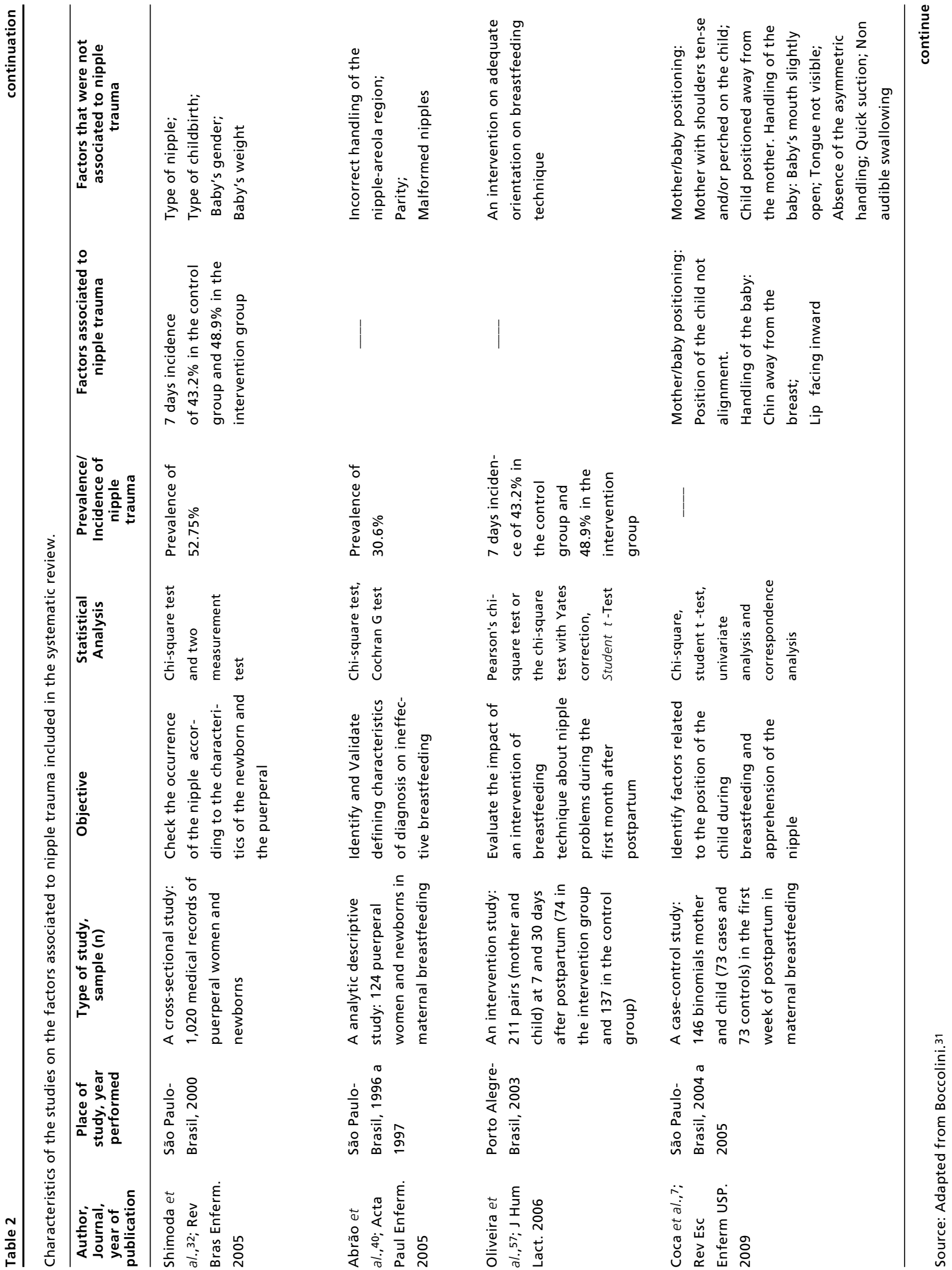




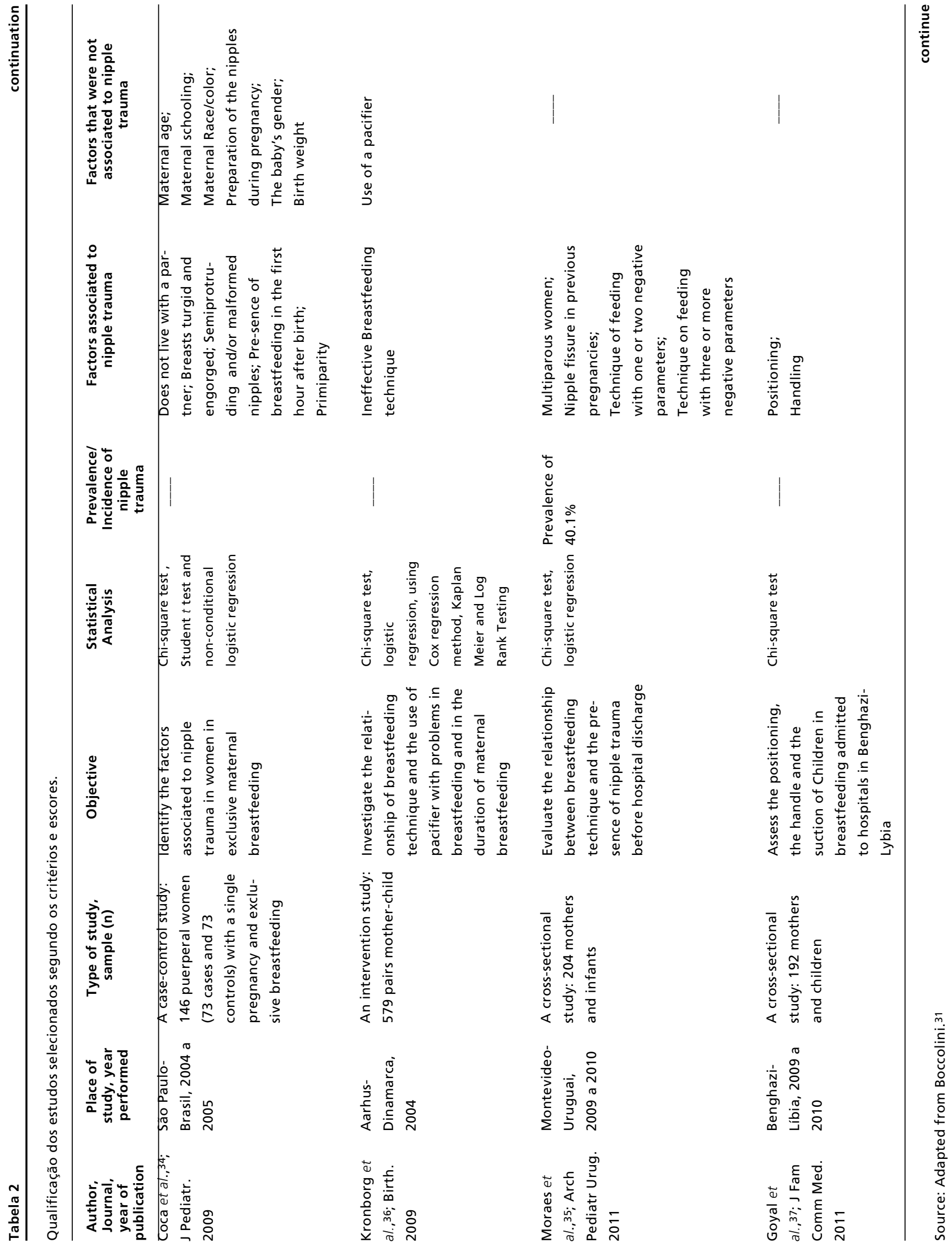




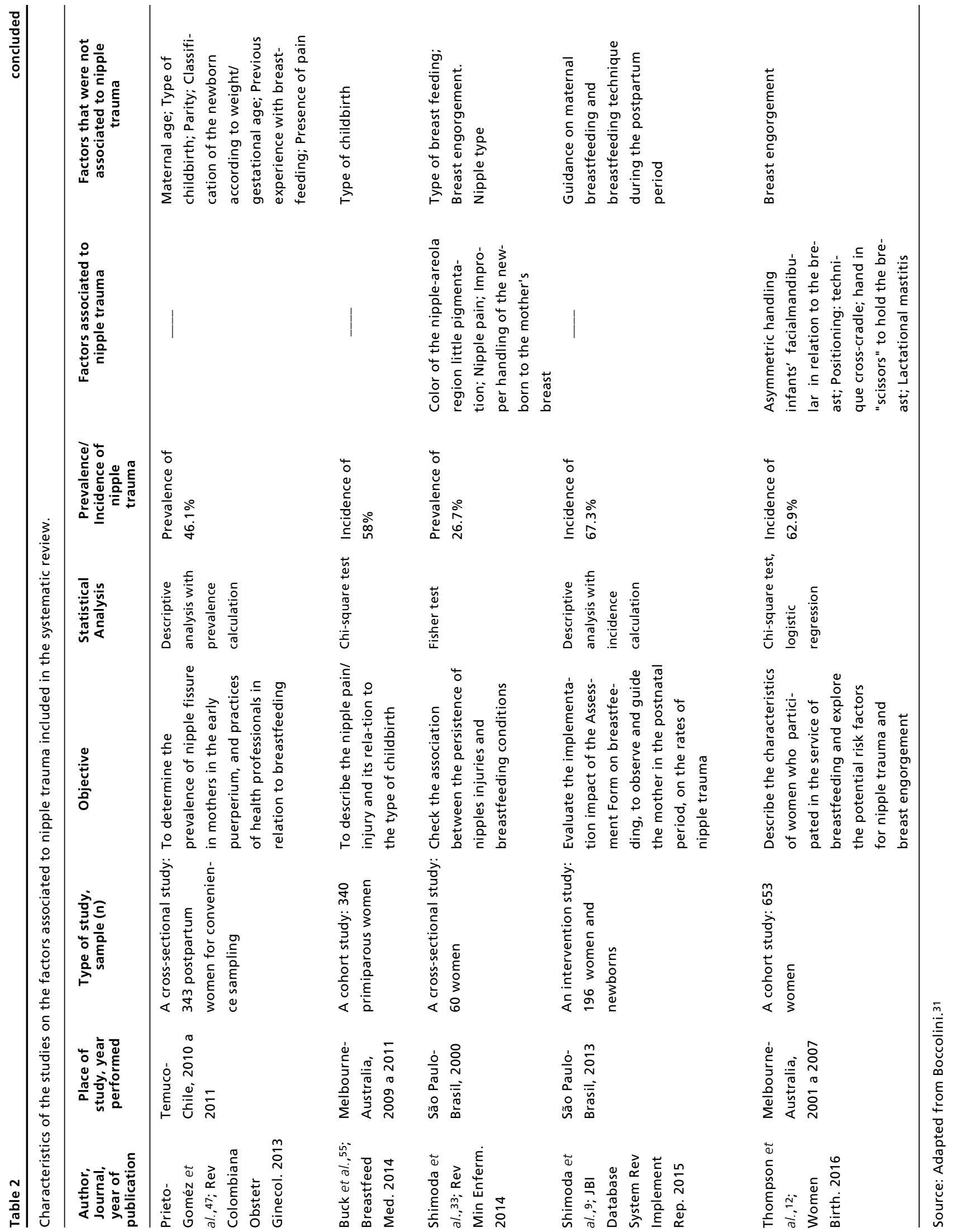




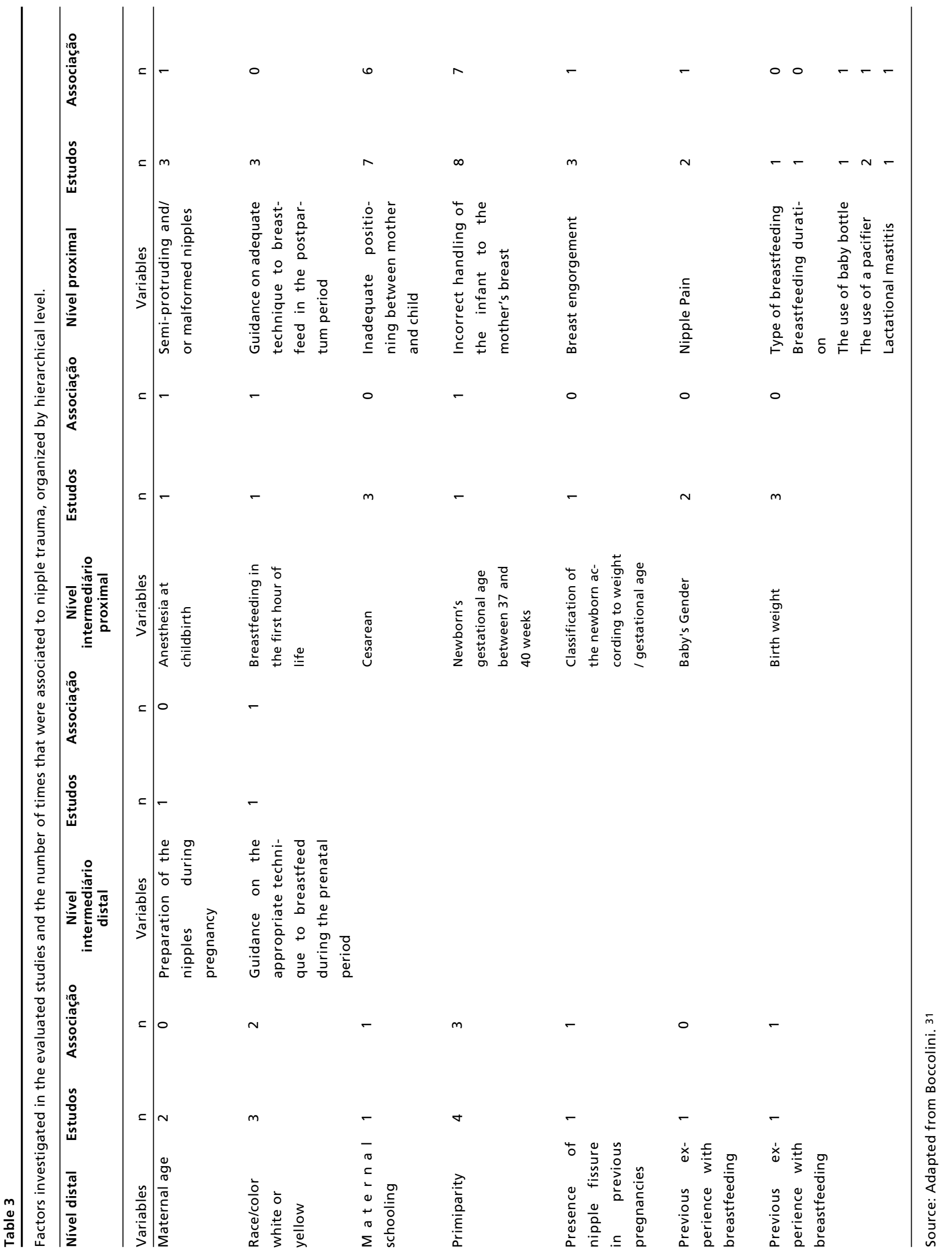




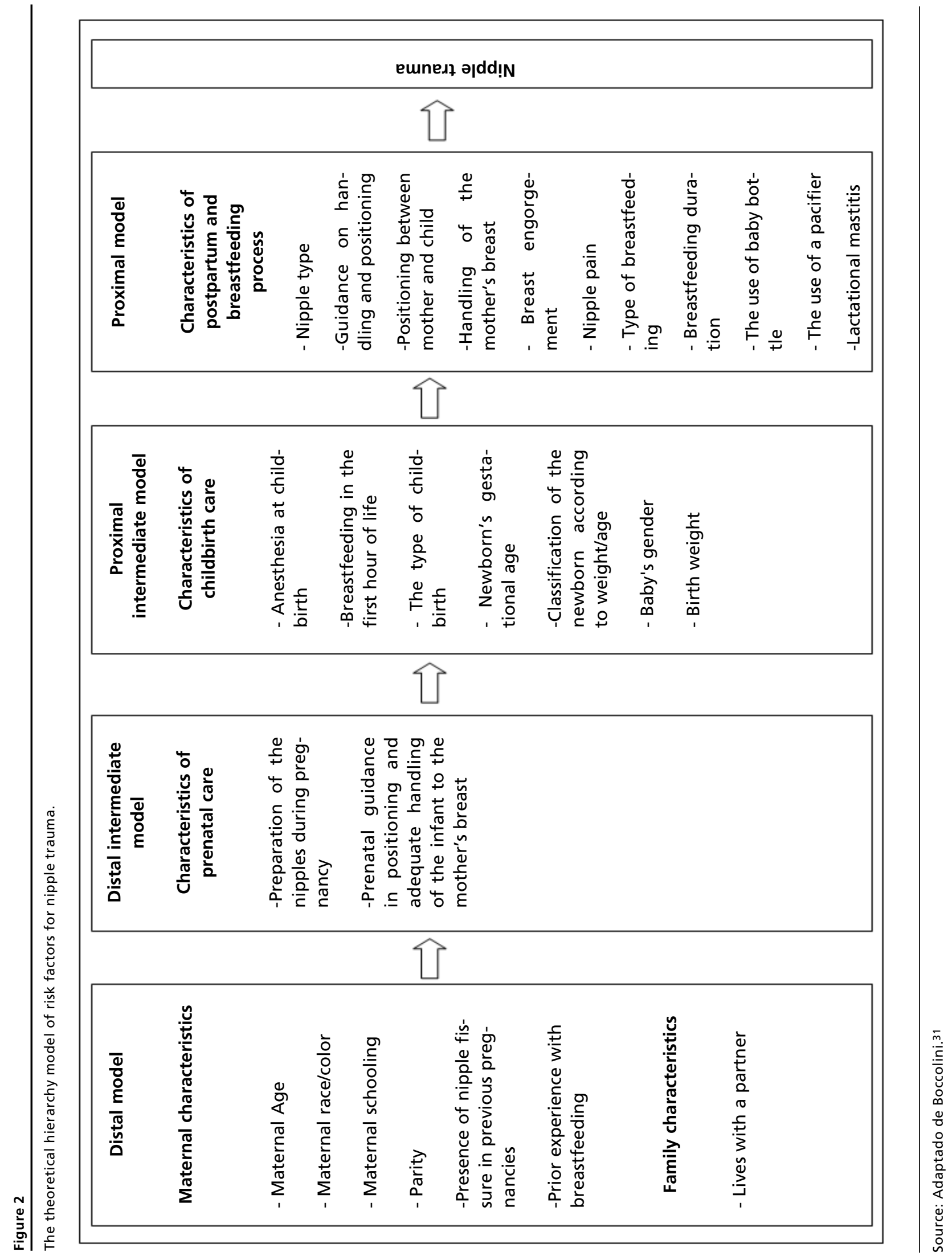


At the distal intermediate level which refers to the characteristics of prenatal care, the guidance received on handling and adequate positioning of the infant to the mother's breast was considered as a protective factor for nipple trauma. ${ }^{23}$ At the proximal intermediate level constituted by the characteristics of childbirth care, an association to nipple injury was observed: the use of anesthesia at childbirth, 32 gestational age between 37 and 40 weeks ${ }^{32}$ and the presence of breastfeeding in the first hour of life. 34

At the proximal level constituted of maternal and newborns characteristics and the health care services related to postpartum and the process of maternal breastfeeding, the variables identified as factors associated to nipple trauma were: semi-protruding and/or malformed nipples, 32 inadequate positioning between mother and child during breastfeeding, 7,12,35-37 incorrect handling of the infant to the mother's breast, 7,12,33,36-38 presence of breast engorgement, 34 nipple pain, 33 lactational mastitis, 12 baby bottle feeding 39 and/or pacifier. 39

\section{Discussion}

This systematic review investigated epidemiological studies on nipple trauma. The selected studies demonstrated differences in prevalence rates between $26.7 \%$ to $52.75 \%$, as well as in the estimated incidences that ranged from $16 \%$ to $100 \%$. The variability of the measurements found can be explained, among other reasons, by special features in the definition of the outcome, by the study design, different sample sizes or losses on the follow-ups registered in some studies.

The first week after childbirth, it was the period of the greatest appearance of nipple injuries. $32,34,39,40$ Corroborating with this finding to other studies, 41,42 that identified a higher incidence of nipple injury between the second and third day of postpartum. However, teaching the technique of breastfeeding within the first few days after childbirth and the observation of breastfeeding are essential for the prevention and reduction of nipple trauma.

The incorrect handling of the infant to the mother's breast and the inadequate positioning between mother and child were associated to nipple trauma in most number of studies, followed by primiparity and mother 's race/color white or yellow. In the adequate handling to the breast, the child must be with the lips facing out, mouth wide open, the appearance of rounded cheeks, the presence of more areola above the child's mouth (asymmetric handling) and the chin touching the mother's breast. In the proper placement during breastfeeding, the child's body is near and facing the mother, the head and body aligned, the mouth is the same height as the nipple and the infant's buttocks supported. 43,44

Regarding to the infant's handling, studies have identified as unfavorable parameters of the child's chin away from the breast, 34 the bottom lip facing in, 34 the mouth a little opened 38 and absence of the asymmetrical handling. ${ }^{38}$ However, in another study, the criterion of asymmetric handling was not a sufficient parameter for defining this, because in the assessment of breastfeeding some mothers had a small areola circumference and for this reason all the nipple-areola region remained covered by the neonate's lips, hindering the view on the observation of breastfeeding. 33

Inadequate technique in breastfeeding, including the handling and the positioning between mother and child was also associated to breast problems in other studies. $12,35-37$ In this aspect, intervention actions are essential to prevent the appearance of nipple injuries. $34,36,38$

In this current study, the set of variables that has been identified as potential predictors were classified in hierarchical levels, according to the proximity of the factor exposure with the outcome. At the proximal level, which refers to the characteristics of the postpartum and breastfeeding process, in addition to the incorrect handling of the infant and the inadequate positioning between mother and child were also considered as predictors of nipple trauma, the nipple type was not favorable, the presence of breast engorgement, nipple pain, the use of baby bottle and pacifier. The occurrence of lactational mastitis was also included in this level.

It was observed that nursing mothers with breasts engorgement presented a greater chance to occur nipple trauma. ${ }^{7}$ In these cases, the complex area of the nipple-areola region is flatten so more distortion of the anatomy of the breast, a fact that makes it difficult to handle the infant correctly, leading to nipples injuries. 45,46 Women with malformed nipples also presented greater chances to occur injuries when compared to breastfeeding women with protruding nipples format. 32

The nipple injury was associated to pain, 33 a common symptom that may occur in the first few hours of maternal breastfeeding 47 and is indicated as inadequacy of handling the infant to the mother's breast. 24 Women who experienced pain during breastfeeding should be assessed by health professionals, with the observation on the feeding tech- 
nique. ${ }^{24}$ The diagnosis and early treatment of handling and inadequate positioning can reduce the consequences generated by the women, among all of this, the interruption of maternal breastfeeding. ${ }^{47}$

In relation to the use of baby bottles and/or pacifier, children can present a pattern of inadequate suction of the mother's breast by distorting the movements of the tongue, causing the so-called "nipple confusion". In the usual behavior on the suction of a baby bottle, children use the tongue to control the flow of the milk from the tip of the latex nozzle, while the correct suction on the mother's breast, is the tongue moving in waving motion to remove the milk, protecting the nipple from frictions and injuries. 48,49 Studies have reported an association between pacifier use and the technique of inadequate breastfeeding. 48,50 However, a review of 14 articles found little evidence of the causal relationship between the use of pacifiers and baby bottles and nipple confusion. 51

The local or general lactational mastitis is joined to nipple trauma. 12 The authors emphasized this because it is a retrospective study and they did not allow the determination of cause and effect. Other studies have related nipple fissure to the development of lactational mastitis. $11,16,17,18,22,52$

At the proximal intermediate level were identified as factors associated to nipple trauma, the use of anesthesia during childbirth, neonates' gestational age between 37 and 40 weeks and breastfeeding in the first hour of life. There was a significant association between epidural anesthesia received by women for a cesarean section or episiotomy in the vaginal delivery having nipple injury. The presence of discomfort and pain in the surgical incision can compromise the positioning of the puerperal to breastfeed her child, resulting in the appearance of nipple injury. 32

Mothers who had cesarean sections were more likely to have problems related to breastfeeding, including nipple fissure, in comparison to women who had vaginal delivery. 53,54 However, there were no relationship observed between nipple injury with the type of childbirth in a cohort study conducted in Australia with 340 primiparous women. 55

The incidence of nipple injury in mothers with newborns at term (37 to 40 weeks of gestation) was higher when compared to preterm infants of 32 to 37 weeks. ${ }^{32}$ It may be inferred that the strongest force of suction and a better application of the breast tissue during breastfeeding of children born at term have contributed for nipple injury.

Breastfeeding in the first hour of life was identified as a risk factor for nipple injury, 34 which according to the authors, the result found is probably related to the handling and the incorrect positioning of the child to be placed for breastfeeding and this is not the strategy of breastfeeding in the first hour of life, as recommended for early establishment in maternal breastfeeding. 56

At the distal intermediate level, it was noted that guidance received during prenatal care on the technique of breastfeeding was a protective factor against the occurrence of nipple trauma, reflecting on the importance of the completeness care during this period to prevent nipple injuries and its possible consequences, although only one study has evaluated this feature. ${ }^{23}$ Women who have had prenatal guidance presented less pain and nipple trauma during the first four days after childbirth, in addition to a higher prevalence of maternal breastfeeding within the six weeks after childbirth. 23

Educational programs in prenatal care can provide necessary knowledge, as well as contribute to increase the mother's confidence in her ability to breastfeed, important characteristics to initiate breastfeeding. The synergism of actions developed during the gestation and after the birth of the child is fundamental to prevent nipple injuries. A study performed with the puerperal women between the second and the fourth day postpartum showed that only $60 \%$ of women remembered about the guidance they received on breastfeeding during the prenatal period. 47 Similar to the guidance on breastfeeding technique performed only in the postpartum period which did not determine a positive effect in preventing nipple problems. 9,57

At the distal level of the hierarchical model of this study, nipple trauma was considered as risk factors for mothers' race/color white or yellow, primiparity, presence of nipple fissure in previous pregnancies and mothers who did not live with a partner.

Nursing mothers' race/white or yellow color were related to nipple injury. ${ }^{32,33}$ Dark skinned women are less likely to present nipple injuries during breastfeeding due to the greater amount of melanin and consequently the increase of skin resistance to nipple trauma caused by the infants' suction. ${ }^{32}$ However, in a case-control study, breastfeeding women's skin color is not self-referred as a determinant factor for the appearance of nipple trauma. ${ }^{7}$

The primiparity is a factor that independently can be associated to nipple trauma. A study with puerperal women on exclusive maternal breastfeeding showed that primiparous women have a greater chance to develop nipple injury when 
comparing those with more than one child. 7

The educational program to correct positioning during the postpartum period did not show statistical significance in preventing nipple trauma in an intervention study with primiparous women. 58 The results of another study 37 indicated that most multiparous women presented satisfactory parameters in relation to the positioning and handling, which could be a result of the previous experience in the practice of maternal breastfeeding. It should be noted that primiparous women need different approaches to establish breastfeeding.

The presence of nipple fissure in previous gestation was associated to the appearance of nipple injuries in 204 women evaluated before hospital discharge. 35 In this study, it considered only the history of breast complications, no information about the characteristics of the skin and the nipple.

Nipple trauma was associated to the absence of the partner. ${ }^{34}$ The authors discussed that the lack of the partner could leave the woman more insecure, making the practice of breastfeeding difficult. The lack of emotional and social support could interfere in the process of maternal breastfeeding and the occurrence of nipple injuries. 47

The mother's age, the schooling level, previous experience with breastfeeding, preparing the nipples during the gestation, the type of childbirth, classification of the newborn according to weight and gestational age, the child's gender, birth weight, guidance on positioning the child in the postpartum period, type and duration of maternal breastfeeding, there were no determinate factors for nipple trauma among the selected studies. However, the hierarchical model was kept due to the understanding of the biological plausibility of these characteristics as possible factors associated to nipple trauma.

There were no studies identifying the contextual level approach in respect to the factors related to the support actions and protection on maternal breastfeeding within the location (city/town), so this level will not be included in the hierarchical model proposed.

Regarding to the limitations of this present study, there is the possibility of not identifying and selecting some studies about the topic addressed and,

\section{References}

1. Gartner LM, Morton J, Lawrence RA, Naylor AJ, O'Hare D, Schanler RJ, Eidelman AI. Breastfeeding and the use of human milk. Pediatrics. 2005; 115(2):496-506. for not entering in the search criteria that was established. Another limitation was observed regarding the methodological quality of the studies found, however, only four used the logistic regression as a multivariate analysis, limiting the possibility to identify confounders and effect modifiers. Furthermore, in virtue of the heterogeneity of the studies listed, it was not possible to employ the use of quantitative synthesis of the results by means of meta-analysis.

\section{Final Considerations}

Nipple trauma is a common problem among women in the lactational period, which can start immediately after the delivery. The main risk factors identified were: the incorrect handling of the infant to the mother's breast, the inadequate positioning between mother and child, primiparity and maternal race/color defined as white or yellow, characteristics observed, respectively in seven, six, three and two reviewed studies.

Other factors were identified as determinants for nipple trauma in at least one study: the presence of nipple fissure in previous gestations, mothers who did not live with a partner, the use of anesthesia during delivery, newborn's gestational age between 37 and 40 weeks, semi-protruding and/or malformed nipples, presence of breast engorgement, nipple pain, lactational mastitis, the use of baby bottle and/or pacifier. The guidance received on handling and appropriate positioning during the prenatal care was shown as a protective factor for nipple trauma.

The characteristics related to postpartum and maternal breastfeeding, classified in the proximal hierarchical level were the most investigated and identified as risk factors, indicating that the preventive actions aiming to reduce nipple trauma should be developed mainly in the postpartum period, with teaching techniques of breastfeeding. Although the results analyzed by different levels contribute to the understanding of the processes involved in the occurrence of nipple injuries, the current study does not have a definitive conclusion, since the practice of $\mathrm{MB}$ is the result of the interaction of multiple individual and contextual determinants.

2. Toma TS, Rea MF. Benefícios da amamentação para a saúde da mulher e da criança: um ensaio sobre as evidências. Cad Saúde Pública. 2008; 24 (2): 235-46. 
3. Brasil. Ministério da Saúde. Secretaria de Atenção à Saúde. Departamento de Atenção Básica. Saúde da criançanutrição infantil: aleitamento materno e alimentação complementar. Brasília, DF; 2009.

4. WHO (World Health Organization). Infant and young child feeding: Model chapter for text books for medical students and allied health professionals. Geneva; 2009.

5. Riordan J, Bibb D, Miller M, Rawlins T. Predicting breastfeeding duration using the LATCH breastfeeding assessment tool. J Hum Lact. 2001; 17 (1): 20-3.

6. Ahluwalia IB, Morrow B, Hsia J. Why do women stop breastfeeding? Findings from the pregnancy risk assessment and monitoring system. Pediatrics. 2005; 116 (6): 1408-12.

7. Coca KP, Gamba MA, Silva RSE, Abrão ACFV. Factors associated with nipple trauma in the maternity unit. J Pediatr. 2009; 85 (4): 341-5.

8. Vieira GO, Martins CC, Vieira TO, Oliveira NF, Silva LR. Factors predicting early discontinuation of exclusive breastfeeding in the first month of life. J Pediatr. 2010; 86 (5): 441-4

9. Shimoda GT, Soares AV, Aragaki IMM, Mcarthur A. Preventing nipple trauma in lactating women in the University Hospital of the University of Sao Paulo: a best practice implementation project. JBI Database System Rev Implement Rep. 2015; 12 (13): 212-32.

10. Ziemer MM, Pigeon JG. Skin changes and pain in the nipple during the 1st week of lactation. J Obstet Gynecol Neonatal Nurs. 1993; 22 (3): 247-56.

11. Giugliani ERJ. Common problems during lactation and their management. J Pediatr. 2004; 80 (5): 147-54.

12. Thompson R, Kruske S, Barclay L, Linden K, Gao Y, Kildea S. Potential predictors of nipple trauma from an inhome breastfeeding programme: a cross-sectional study. Women Birth. 2016; 29 (4): 336-44

13. Coca KP, Abrão ACFV. Avaliação do efeito da lanolina na cicatrização dos traumas mamilares. Acta Paul Enferm. 2008; 21 (1): 11-6

14. Cervellini MP, Gamba MA, Coca KP, Abrão ACFV. Injuries resulted from breastfeeding: a new approach to a known problem. Rev Esc Enferm USP. 2014; 48 (2): 346-56.

15. WHO (World Health Organization). La alimentación del lactante y del niño pequeño. Geneva; 2010.

16. Foxman B, D'Arcy H, Gillespie B, Bobo JK, Schwartz K. Lactation mastitis: occurrence and medical management among 946 breastfeeding women in the United States. Am J Epidemiol. 2002; 155: 103-14.

17. Giugliani ERJ. Lack of scientific evidence for the treatment of nipple traumas. J Pediatr. 2003; 79 (3): 197-8.

18. Cullinane M, Amir LH, Donath SM, Garland SM, Tabrizi SN, Payne MS, Bennett CM. Determinants of mastitis in women in the CASTLE study: a cohort study. BMC Fam Pract. 2015; 16 (1): 181

19. Livingstone VH, Willis CE, Berkowitz J. Staphylococcus aureus and sore nipples. Can Fam Physician. 1996; 42: 654 9.
20. Amir LH. Candida and the lactating breast: predisposing factors. J Hum Lact. 1991; 7 (4): 177-81.

21. Tanguay KE, Mcbean MR, Jain E. Nipple candidiasis among breastfeeding mothers. Case-control study of predisposing factors. Can Fam Physician. 1994; 40: 1407-13.

22. Vieira GO, Silva LR, Mendes CMC, Vieira TO. Mastite lactacional e a Iniciativa Hospital Amigo da Criança, Feira de Santana, Bahia, Brasil. Cad Saúde Pública. 2006; 22(6): 1193-200.

23. Duffy ER, Percival P, Kershaw E. Positive effects of an antenatal group teaching session on postnatal nipple pain, nipple trauma and breast feeding rates. Midwifery. 1997; 13: $189-96$

24. WHO (World Health Organization). Technical consultation on postpartum and postnatal care. Geneva; 2010.

25. Moher D, Liberati A, Tetzlaff J, Altman DG, Prisma Group. Reprint-Preferred Reporting Items for Systematic Reviews and Meta-Analyses: The PRISMA Statement. Phys Ther. 2009; 89(9): 873-80.

26. NCBI (National Center for Biotechnology Information). [acesso em 2016 jun 16]. Disponível em: http://www.ncbi. nlm.nih.gov/pubmed.

27. BVS (Biblioteca Virtual em Saúde). [acesso em 2016 jun 18]. Disponível em: http://regional.bvsalud.org

28. ScienceDirect. [acesso em 2016 jun 18]. Disponível em: http://www.sciencedirect.com/science/search.

29. Vieira TO, Vieira GO, Martins CC, Santana GS, Silva L. Intenção materna de amamentar: revisão sistemática. Ciênc Saúde Coletiva. 2016; 21 (12): 3845-58.

30. Boccolini CS, Carvalho ML, Oliveira MIC, Vasconcellos AGG. Fatores associados à amamentação na primeira hora de vida. Rev Saúde Pública. 2011; 45 (1): 69-78.

31. Boccolini CS. Aleitamento materno: determinantes sociais e repercussões na saúde infantil [tese]. Rio de Janeiro: Ministério da Saúde- Fundação Oswaldo Cruz- Escola Nacional de Saúde Pública Sérgio Arouca; 2012.

32. Shimoda GT, Silva IA, Santos JLF. Characteristics, frequency and factors present in nipples damage occurence in lactating women. Rev Bras Enferm. 2005; 58 (5): 52934

33. Shimoda GT, Aragaki IMM, Sousa CA, Silva IA. Associação entre persistência de lesão de mamilos e condições de aleitamento materno. Rev Mineira Enferm. 2014; 18 (1): 68-74.

34. Coca KP, Gamba MA, Silva RSE, Abrão ACFV. Does breast feeding position influence the onset of nipple trauma? Rev Escola Enferm USP. 2009; 43 (2): 446-52.

35. Moraes M, Silva L, Faliú B, Sosa C. Técnica de alimentación a pecho y aparición de trauma del pezón previo al alta hospitalaria. Arch Pediatr Urug. 2011; 82 (1): 10-17.

36. Kronborg H, Vaeth M. How Are Effective Breastfeeding Techniqueand Pacifier Use Related to Breastfeeding Problems and BreastfeedingDuration? Birth. 2009; 36: 3442. 
37. Goyal RC, Banginwar AS, Ziyo F, Toweir AA Breastfeeding practices: Positioning, attachment (latch-on) and effective suckling - A hospital-based study in Libya. J Fam Comm Med. 2011; 18 (2): 74-9.

38. Weigert EML, Giugliani ERJ, França MCT, Oliveira LD, Bonilha ALL, Espiríto Santo LC, Köhler CV. The influence of breastfeeding technique on the frequencies of exclusive breastfeeding and nipple trauma in the first month of lactation. J Pediatr. 2005; 81 (4): 310-6.

39. Centuori S, Burmaz T, Ronfani L, Fragiacomo M, Quintero S, Pavan C, Davanzo R, Cattaneo A. Nipple care, sore nipples, and breastfeeding: a randomized trial. J Hum Lact. 1999; 15 (2): 125-30

40. Abrão ACFV, Gutierrez MGR, Marin HF. Diagnóstico de Enfermagem Amamentação Ineficaz - Estudo de identificação e validação clínica. Acta Paul Enferm. 2005; 18 (1): 46-55.

41. Espiríto Santo LC, Oliveira LD, Giugliani ER. Factors associated with low incidence of exclusive breastfeeding for the first 6 months. Birth. 2007; 34: 212-9.

42. Abou-Dakn M, Fluhr JW, Gensch M, Wöckel A. Positive Effect of HPA Lanolin versus Expressed Breastmilk on Painful and Damaged Nipples during Lactation. Skin Pharmacol Physiol. 2011; 24: 27-35.

43. UNICEF (United Nations Children's Fund). Breastfeeding management and promotion in a babyfriendly hospital: an 18-hour course for maternity staff. New York; 1993.

44. UNICEF (United Nations Children's Fund). Breastfeeding management and promotion in a babyfriendly hospital: an 20-hour course for maternity staff. New York; 2009.

45. Cotterman KJ. Reverse pressure softening: a simple tool to prepare areola for easier latching during engorgement. J Hum Lact. 2004; 20 (2): 227-37.

46. WHO (World Health Organization), UNICEF (United Nations Children's Fund). Baby-Friendly Hospital Initiative: revised, updated and expanded for integrated care. Geneva: World Health Organization; 2009.

47. Prieto-Gómez R, Baeza-Weinmann B. Lactancia materna: Prevalencia de grietas y dolor en mujeres que amamantan, región de la araucanía, Temuco, Chile. 2010-2011. Rev Colombiana Obstetr Ginecol. 2013; 64 (3): 229-33.
48. Righard L. Are breastfeeding problems related to incorrect breastfeeding technique and the use of pacifiers and bottles? Birth. 1998; 25: 40-4

49. Tait P. Nipple pain in breastfeeding women: Causes, treatment, and prevention strategies. J Midwifery Women's Health 2000; 45(3); 2012-5.

50. Howard CR, Howard FM, Lanphear B, Blieck EA, Eberly S, Lawrence RA. The effects of early pacifier use on breastfeeding duration. Pediatrics. 1999; 103 (3): E33.

51. Zimmerman E, Thompson K. Clarifying nipple confusion. J Perinatol. 2015; 35 (11): 895-9.

52. Kvist LJ, Hall-Lord ML, Larsson BW. A descriptive study of Swedish women with symptoms of breast inflammation during lactation and their perceptions of the quality of care given at a breastfeeding clinic. Int Breastfeed J 2007; 2:2

53. Boskabadi H, Ramazanzadeh M, Zakerihamidi M, Rezagholizade OF. Risk factors of breast problems in mothers and its effects on newborns. Iran Red Crescent Med J. 2014; 16 (6): 8582.

54. Suresh S, Sharma KK, Saksena M, Thukral A, Agarwal R, Vatsa M. Predictors of breastfeeding problems in the first postnatal week and its effect on exclusive breastfeeding rate at six months: experience in a tertiary care centre in Northern India. Indian J Public Health. 2014; 58 (4): 270-3.

55. Buck ML, Amir LH, Cullinane M, Donath SM. Nipple pain, damage, and vasospasm in the first 8 weeks postpartum. Breastfeed Med. 2014; 9 (2): 56-62.

56. WHO (World Health Organization). Evidence for ten steps to successful breastfeeding. Geneva: WHO/CHD/98.9; 1998.

57. Oliveira LD, Giugliani ER; Espírito Santo LC, França MC, Weigert EML, Kohler CV, Lourenzi Bonilha AL. Effect of Intervention to Improve Breastfeeding Technique on the Frequency of Exclusive Breastfeeding and LactationRelated Problems. J Hum Lact. 2006; 22 (3): 315-21.

58. Henderson A, Stamp G, Pincombe J. Postpartum positioning and attachment education for increasing breastfeeding: a randomized trial. Birth. 2001; 8 (4): 236-42.

Received on August 31, 2016

Final version presented on February 8, 2017

Approved on February 16, 2017 